Proceedings - 19th International Conference - IEEE/EMBS Oct. 30 - Nov. 2, 1997 Chicago, IL. USA

\title{
A SIMULATION MODEL OF THE ELECTRICAL CHARACTERISTICS OF HUMAN MYELINATED SENSORY NERVE FIBERS
}

\author{
W.A. Wesselink, J. Holsheimer, Z. Sönmez, H.B.K. Boom \\ Institute for Biomedical Technology, University of Twente \\ P.O. Box 217, 7500 AE, Enschede, The Netherlands \\ email:w.a.wesselink@el.utwente.nl
}

\begin{abstract}
A new nerve fiber model has been developed, incorporating electrical characteristics of human myelinated sensory nerve fibers. It will be used to determine the response of myelinated somatosensory nerve fibers in the spinal cord to electrical stimulation with an epidurally placed electrode.
\end{abstract}

Index terms - Spinal cord stimulation, human sensory nerve fiber, simulated action potential, chronaxie

\section{Introduction}

Spinal cord stimulation (SCS) for the management of chronic pain implies electrical stimulation of large myelinated somatosensory dorsal column (DC) fibers to block pain pathways to the brain. At the University of Twente, a computer model has been developed, which simulates the direct effects of SCS [1]. This model consists of a volume conductor model and a nerve fiber model, representing the spinal cord and surrounding anatomical structures, and the electrical behavior of the myelinated nerve fibers in the spinal cord, respectively.

After calculation of the potential field in the inhomogeneous volume conductor model resulting from electrical stimulation, the response of myelinated nerve fibers in the spinal cord is determined with an electrical equivalent cable model, as presented by McNeal [2]. Until now, the characteristics of the nerve fiber model were based on experimental data from rabbit nerve fibers [3], and adapted for use at $37^{\circ} \mathrm{C}$. In the current study, a new model is presented, merely based on properties of human nerve fibers.

Schwarz et al. [4] have presented results from experiments on single human myelinated sensory nerve fibers. They recorded sodium and potassium currents under current- and voltage clamp conditions at room temperature. Morphometric data concerning the myelin sheath thickness and internodal distance of human myelinated sensory nerve fibers were presented by Behse [5], who has shown that the ratios of fiber diameter, axon diameter and internodal length are not constant, as previously assumed, but vary with the fiber diameter. Schalow et al. [6] showed that the ratio between the conduction velocity and the diameter of human touch stimulated afferents approximates $4 * 10^{6}$, which is considerably less than previously assumed for human (and mammals in general), i.e. $6^{*} 10^{6}$.

These morphometric data, and the dynamics of the human nodal membrane conductance were incorporated in a new nerve fiber model, which will be used to determine the response of sensory nerve fibers in the dorsal columns to epidural electrical stimulation of the spinal cord.

\section{Methods}

From their recordings of action potentials (AP) and membrane currents in human myelinated nerve fiber, Schwarz et al. [4] constructed a mathematical model describing the electrical characteristics of the human node of Ranvier. After we applied temperature correction to these data with Q10 values estimated by Schwarz et al. [4], action potentials could be simulated at $37^{\circ} \mathrm{C}$ at one node of Ranvier.

For application in the SCS computer model, it is necessary to have a McNeal type [2] cable model with compartments for each node of Ranvier. In the Appendix, the complete model is listed. The sodium equilibrium potential was taken from [7], and used to calculate the intracellular sodium concentration. All parameters were taken from literature, except for the intra axonal resistance and the leakage conductance. Both parameters were adjusted to obtain a correct conduction velocity and AP amplitude.

The results presented here were calculated with a simple configuration. A point source was modeled in an infinite, homogeneous medium (resistance $3.0 \Omega \mathrm{m}$ ), containing a single, straight, myelinated nerve fiber at $3 \mathrm{~mm}$ distance, whose presence did not disturb the potential distribution. The nerve fiber model had 51 nodes of Ranvier, all of them made excitable. The nodal membrane current has a capacitive, a leakage, a sodium, and a (fast) potassium component. The sodium and potassium channels are voltage dependent. The myelin sheath is supposed to be a perfect insulator, periodically interrupted at the nodes of Ranvier. 


\section{Results}

The intra axonal resistance was set at $0.35 \Omega \mathrm{m}$, which is less than used in the model of Chiu $(0.7 \Omega \mathrm{m})$. The leakage conductance was calculated to be $950 \mathrm{~S} / \mathrm{m}^{2}$, which is also less than previously used $\left(1280 \mathrm{~S} / \mathrm{m}^{2}\right)$. Figure 1 shows the simulated propagation of an AP along the nodes of Ranvier of a $15 \mu \mathrm{m}$ myelinated nerve fiber. Excitation started at the nodes closest to the point source, and propagation occurd in both directions. The AP's at the 10 adjacent nodes are shown.

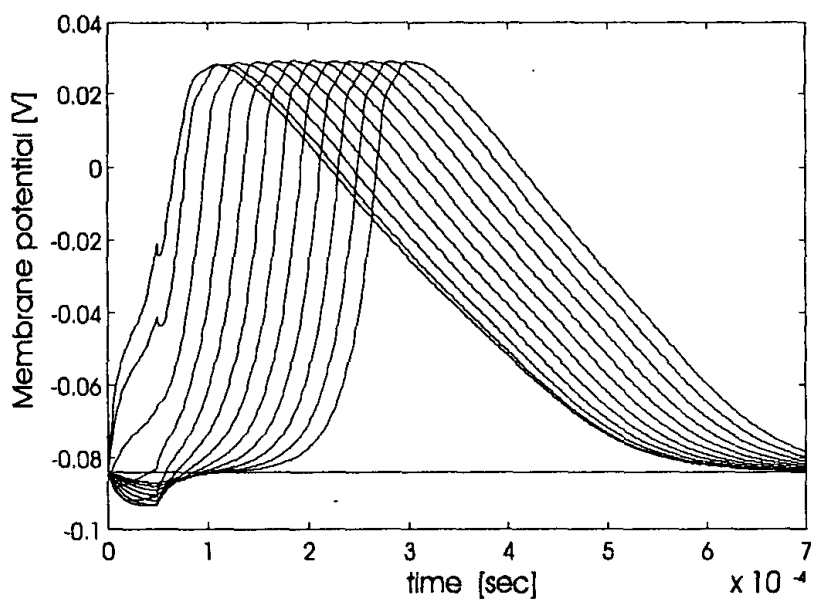

Figure 1: Propagation of an AP along a $15 \mu \mathrm{m}$ fiber

The shape of the AP's is similar to those measured by Schwarz et al. [4] at room temperature, although their duration is less. The amplitude is approximately $113 \mathrm{mV}$. The conduction velocity of the AP is about $62 \mathrm{~m} / \mathrm{s}$, which is less than previous models have shown, but corresponds with the experimental results presented by Schalow et al. [6].

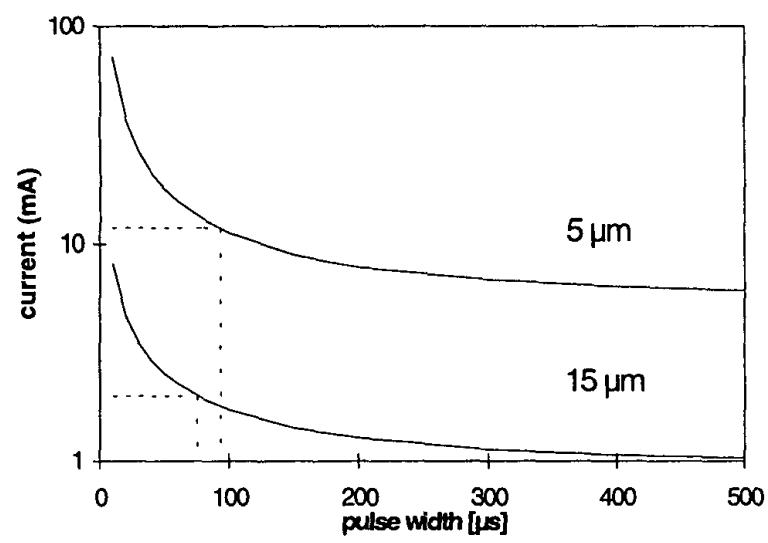

Figure 2: Strength-Duration curve of a 5 and a $15 \mu \mathrm{m}$ fiber; chronaxies indicated by dashed lines
Calculation of strength-duration curves of fibers with diameters between 5 and $15 \mu \mathrm{m}$ with the above mentioned configuration showed that the chronaxies range from 92 to 76 $\mu \mathrm{s}$. This is considerably higher than the Chiu model predicted $(\sim 26 \mu \mathrm{s})$, but fits the experimentally determined values presented by Ranck et al. [8]. Figure 2 shows strength duration curves of a 15 (chronaxie $76 \mu \mathrm{s}$ ) and a $5 \mu \mathrm{m}$ nerve fiber model (chronaxie $92 \mu \mathrm{s}$ ).

\section{Discussion}

A new model has been developed to determine the response of human myelinated DC fibers to SCS with an epidurally placed electrode. Properties determined from human sensory nerve fibers were implemented to simulate the electrical characteristics of these fibers.

Since the propagational behavior of a model completely based on parameters suggested by Schwarz is not correct, and to obtain a close fit with human fiber characteristics determined by Behse [5] and Schalow et al. [6], intra axonal resistance and leakage conductance were adjusted. These fiber parameters are difficult to determine experimentally, and are not well established.

The next step will be the implementation of this nerve fiber model in the SCS computer model, and investigate the properties of the model when stimulation will be performed with electrode configurations different from a point source and in an inhomogeneous volume conductor model.

\section{Acknowledgment}

This research was supported by a grant of Medtronic Inc., Minneapolis, Minnesota

\section{References}

[1] J.J. Struijk, J. Holsheimer, B.K. van Veen, H.B.K. Boom, Epidural spinal cord stimulation: Calculation of field potentials with special reference to dorsal column nerve fibers, IEEE Trans. Biomed. Eng., vol. 38:104110,1991

[2] D.R. McNeal, Analysis of a model for excitation of myelinated nerve, IEEE Trans. Biomed. Eng., vol. BME-23:329-337, 1976

[3] S.Y. Chiu, J.M. Ritchie, R.B. Rogart, D. Stagg, A quantitative description of membrane currents in rabbit myelinated nerve, J. of Physiol., vol. 292:149-166, 1979

[4] J.R. Schwarz, G. Reid, H. Bostock, Action potentials and membrane currents in the human node of Ranvier, Eur. J. Phys., vol, 430:283-292, 1995

[5] F. Behse, Morphometric studies on the human sural nerve, Acta Neurol. Scand., Suppl. 132, vol. 82, 1990 
[6] G. Schalow, G.A. Zäch, R. Warzok, Classification of human peripheral nerve fiber groups by conduction velocity and nerve fiber diameter is preserved following spinal cord lesion, J. Aut. Nervous Syst., vol. 52:125150,1995
[7] A. Scholz, G. Reid, W. Vogel, H. Bostock, Ion channels in human axons, J. Neurophys., vol. 70:1274-1279,1993

[8] J. B. Ranck, Which elements are excited in electrical stimulation of mammalian central nervous system: a review, Brain Res. vol. 98:417-440, 1975

\section{Appendix: parameters at $37^{\circ} \mathrm{C}$}

$\mathrm{d} \quad$ axon diameter $[\mathrm{m}]$

D fiber diameter $[\mathrm{m}]$

L internodal length [m]

1 nodal width, $1.5 \mu \mathrm{m}$

$\pi \mathrm{dl} \quad$ nodal area $\left[\mathrm{m}^{2}\right]$

$\mathrm{c}_{\mathrm{m}} \quad$ membrane capacity, $0.028 \mathrm{~F} / \mathrm{m}^{2}$

$\mathrm{g}_{\mathrm{L}} \quad$ leakage conductance, $950 \mathrm{~S} / \mathrm{m}^{2}$

$\mathrm{p}_{\mathrm{Na}}$ sodium permeability, $0.0704 \mathrm{dm}^{3} / \mathrm{m}^{2} \mathrm{~s}$

$\mathrm{g}_{\mathrm{K}} \quad$ potassium conductance, $300 \mathrm{~S} / \mathrm{m}^{2}$

$\rho_{\mathrm{a}} \quad$ intra axonal resistance, $0.35 \Omega \mathrm{m}$

$\mathrm{E}_{\mathrm{L}} \quad$ leakage equilibrium potential, $-84.14 \mathrm{mV}$

$\mathrm{E}_{\mathrm{Na}} \quad$ sodium equilibrium potential, $61.5 \mathrm{mV}$

$\mathrm{Na}_{\mathrm{o}}$ sodium concentration outside cell, $154 \mathrm{mM}$

$\mathrm{Na}_{\mathrm{i}} \quad$ sodium concentration inside cell, $15.4 \mathrm{mM}$

$E_{K} \quad$ potassium equilibrium potential, $-84 \mathrm{mV}$

$\mathrm{V}$ membrane potential [mV]

$\mathrm{V}_{\mathrm{r}} \quad$ resting membrane potential, $-84 \mathrm{mV}$

$\mathrm{i}_{\mathrm{Na}} \quad$ sodium current $\left[\mathrm{A} / \mathrm{m}^{2}\right]$

$\mathrm{i}_{\mathrm{K}} \quad$ (fast) potassium current $\left[\mathrm{A} / \mathrm{m}^{2}\right]$

$i_{L} \quad$ leakage current $\left[\mathrm{A} / \mathrm{m}^{2}\right]$

$i_{c} \quad$ capacitive current $\left[\mathrm{A} / \mathrm{m}^{2}\right]$

$I_{\text {mem }}$ total nodal membrane current [A]

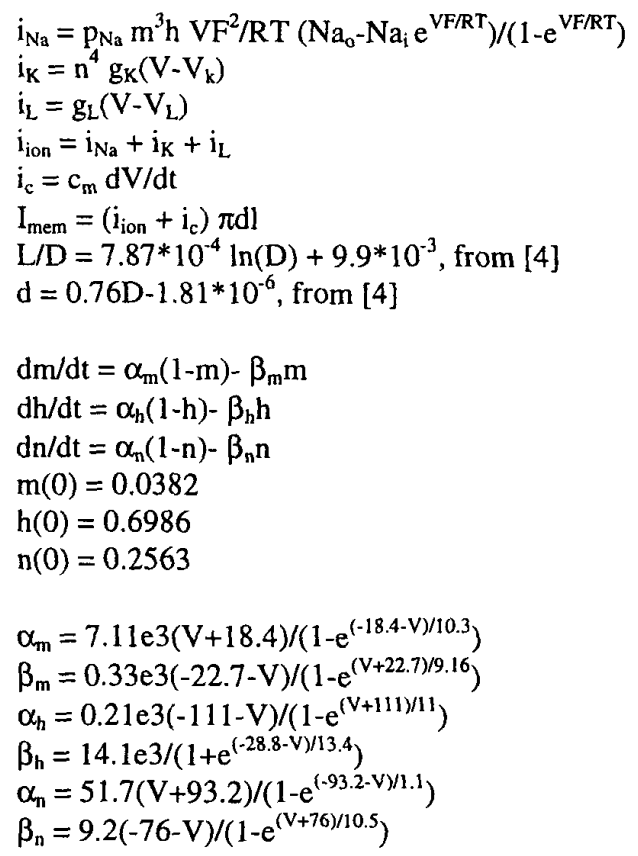

